(2) Open Access Full Text Article

\title{
Assessing the relationship between non-invasive tear break-up time and maximum blink interval values among young adults at Mzuzu University
}

This article was published in the following Dove Press journal: Clinical Optometry

\section{Thokozani Mzumara Joseph Afonne}

Department of Optometry, Faculty of Health Sciences, Mzuzu University, Mzuzu, Malawi
Correspondence: Joseph Afonne Department of Optometry, Faculty of Health Sciences, Private bag 20I, Luwinga, Mzuzu University, Mzuzu, Malawi

Email drchinkatan@gmail.com
Purpose: To assess the relationship between non-invasive tear break-up time (NITBUT) and maximum blink interval (MBI) values among young adults.

Method: The study was conducted at Mzuzu University and involved 98 subjects ( 55 females and 43 males) aged between 18 and 40 years. All subjects were screened under the slit lamp, and were also asked questions to determine their eligibility to participate in the study. NITBUT measurements were taken by checking the discontinuity of the mires on the keratometer. MBI measurements were taken by observing the time period the subject could keep their eyes open without blinking.

Results: There was a positive correlation $\left(r=0.64, r^{2}=0.418, P<0.001\right)$ between NITBUT and MBI values. The relationship between NITBUT and MBI values was similar in both males and females. Furthermore, the study showed that age, as well as gender, is not correlated to NITBUT and MBI values.

Conclusion: There is a positive significant correlation $\left(r=0.64, r^{2}=0.418, P<0.001\right)$ between NITBUT and MBI values. There was no significant difference between the NITBUT and MBI values between males and females. The study has also discovered that there is no correlation between NITBUT and MBI with age and gender.

Keywords: dry eye, tear film stability, non-invasive TBUT, MBI

\section{Introduction}

The National Dry Eye Workshop of 2007 defined dry eye as a multifactorial disease of the tears and ocular surface that results in symptoms of discomfort, visual disturbance, and tear film instability with potential damage to the ocular surface. It is accompanied by increased osmolality of the tear film and inflammation of the ocular surface. ${ }^{1}$

Tear instability is considered a key factor in the mechanism of dry eye.

About $7-35 \%$ of the world's population is said to have dry eye syndrome. ${ }^{1}$ The large variability in the prevalence of dry eye is mainly due to differences in diagnostic tests and climatic differences. Despite its high prevalence, dry eye remains underrecognized in the clinic, due to insufficient data on some diagnostic techniques such as maximum blink interval (MBI) and non-invasive tear break-up time (NITBUT). MBI and NITBUT are non-invasive tear film stability tests which are clinically applicable, with minimal and cheap instrumentation required. ${ }^{2}$

Dry eye patients experience symptoms such as burning sensation, dryness, tearing, and visual disturbances. ${ }^{3-5}$ The symptoms of dry eye can have adverse impacts on health, as well as reduce a person's productivity. This is because dry eye can be 
problematic during activities such as reading, working on a computer, driving, and watching the television. ${ }^{4}$ Furthermore, dry eye has been known to reduce corneal sensitivity, as well as predispose the cornea to infections, keratitis, and inflammation. ${ }^{6-8}$

The clinical diagnosis of dry eye is achieved by a battery of tests, which may include tear osmolality, Schimmer test, phenol red thread test, TBUT (tear break-up time), as well as the use of dry eye questionnaires. Needless to say, there is no single golden test for dry eye diagnosis, but rather a combination of tests is used in making a diagnosis. ${ }^{9}$ The choice of the combination of tests depends on the availability of equipment, and differs from practitioner to practitioner.

Since tear film stability is considered the most important factor in the mechanism of dry eye, employing tests that will assess the tear film in the diagnosis of dry eye is considered precise and effective. ${ }^{10}$ The aim of the study was to assess the relationship between NITBUT and MBI values, both of which are used to assess the tear film and are used in the diagnosis of dry eye. The results realized from the research can help in the diagnosis and possible management of dry eye by providing eye care professionals with readily available techniques.

\section{Methodology}

The study was conducted at Mzuzu University, located in Mzuzu city in the northern region of Malawi. The study targeted Mzuzu University students between 18 and 40 years of age. Based on a formula by Yamane, ${ }^{11}$ a sample of 98 students was selected from the total population by using a stratified random sampling technique. The population was divided into stratum by faculty, and the student percentage distribution as per faculty was used to calculate the number of participants from each faculty. Subjects within each faculty were selected using a simple random sampling method to ensure accurate representation of the total population.

As an exclusion criteria, subjects were checked for conjunctivitis, a history of ocular surgery, lid abnormalities, current contact lens use, current use of eye drops, and contraceptive pills use.

The study was approved by the Faculty of Health Sciences Research Committee and the Mzuzu University Research Directorate. Permission to conduct the study at Mzuzu University was granted through the university registrar's office.

All subjects were informed of the non-invasive nature of the procedures involved, as well as the benefits of the study, before signing a written consent form to participate in the study. The researcher maintained the anonymity of the participants; as such, the identity of the participants and their information remained confidential during and after the study. The participants were also informed that their participation was voluntary, and that they were free to withdraw at any point during the study.

\section{Procedures}

To measure for NITBUT, the subject was positioned on a well calibrated keratometer and three NITBUT readings were taken (using a stop watch) on the subjects' right eye only, by noting the first sign of distortion of the mires after a complete blink. ${ }^{12}$ The average of the three readings was considered the subjects' NITBUT. This was done to reduce measuring errors incurred during such procedures. If the subject blinked before the distortion of the mires was noted, the procedure was stopped and the subject was allowed to blink several times before redoing the test.

To measure for MBI, the participant sat under normal conditions and was asked to blink and keep their eyes open for the longest time possible. ${ }^{13} \mathrm{~A}$ stop watch was used to note the time from the last blink to when the subject could no longer keep their eyes open. The average of three consecutive readings was considered the subjects' MBI. The subjects were not made aware that the MBI reading was being taken.

In order to minimize potential bias due to the subjective nature of the tests, the data were collected by three different investigators. An average of three measurements from each investigator was considered the final reading of the test.

\section{Results}

The statistical analysis was performed using SPSS 16.0. The correlations between the NITBUT and MBI values were analyzed using Pearson's $r$ correlation test. Bar graphs were used to graphically illustrate descriptive statistics.

The study employed a sample size of 98 participants, which included 55 females and 43 males. The participants' age ranged from 18 to 40 years. MBI values ranged from 9 to $33 \mathrm{~s}$, with mean of $21 \mathrm{~s}(\mathrm{SD}=5.99 \mathrm{~s})$. NITBUT values ranged from 6 to $23 \mathrm{~s}$, with a mean of $16 \mathrm{~s}(\mathrm{SD}=3.55 \mathrm{~s})$.

\section{Relationship between NITBUT and MBI values}

There was a significant positive correlation $\left(\mathrm{r}=0.6, \mathrm{r}^{2}=0.418\right.$, $P<0.001$ ) between NITBUT and MBI values, as illustrated in Figure 1. There was no significant difference in the NITBUT and MBI values between genders $(\mathrm{t}(96)=0.4, P=0.629)$. That is, there was a positive correlation between NITBUT and MBI values among males $(\mathrm{r}=0.6, \mathrm{n}=43)$ and females $(\mathrm{r}=0.6, \mathrm{n}=55)$. 


\section{Distribution of NITBUT and $\mathrm{MBI}$ values according to age}

The results of our study show that there was no correlation between MBI values and age $(P=0.805)$, as well as NITBUT and age $(P=0.641)$, as illustrated in Figures 2 and 3, respectively.

\section{Distribution of $\mathrm{MBI}$ values according to gender}

An independent sample $t$-test was conducted to compare the mean of MBI values between males and females. The average of MBI values among males and females was equal. Males had a mean MBI value of $21 \mathrm{~s}(\mathrm{SD}=6.01 \mathrm{~s})$, and females

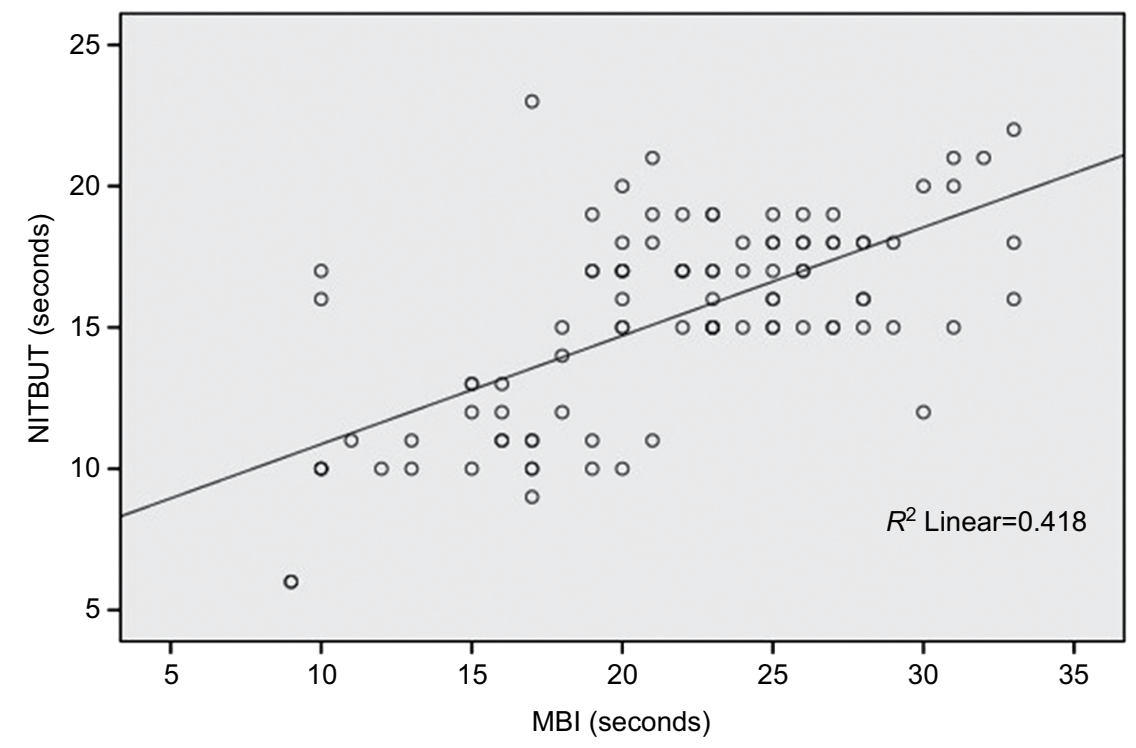

Figure I Relationship between NITBUT and MBI values $(r=0.6, P<0.00 I, n=98)$.

Abbreviations: NITBUT, non-invasive tear break-up time; $\mathrm{MBI}$, maximum blink interval.

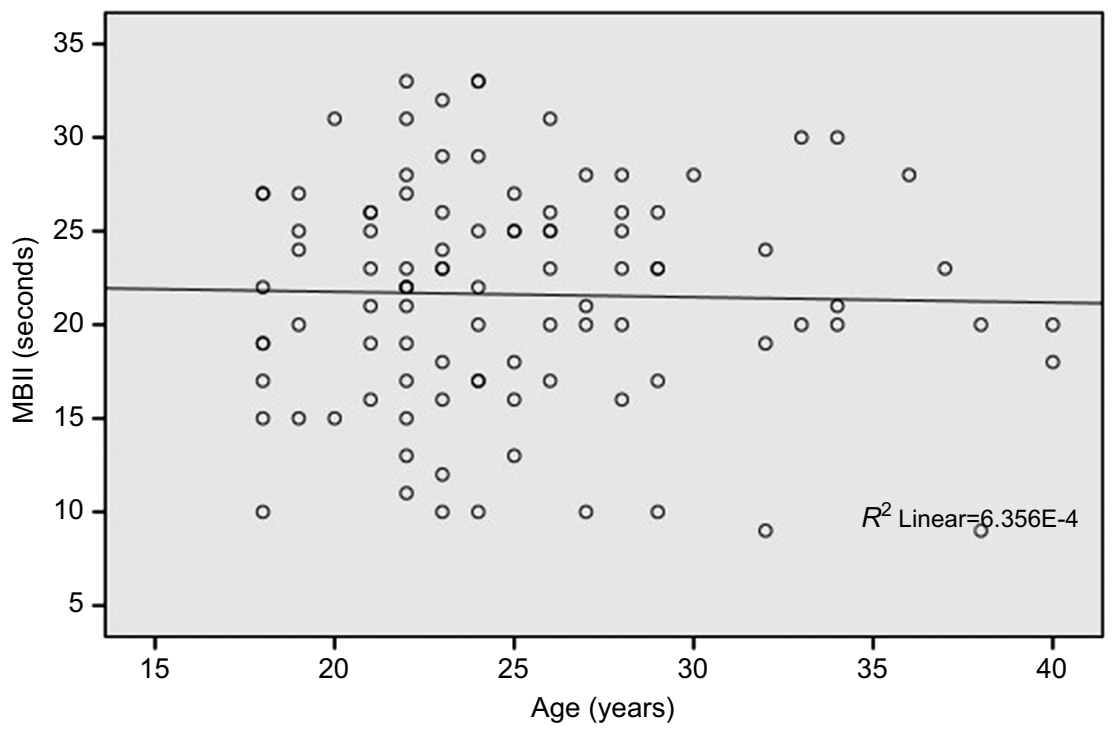

Figure 2 Distribution of $M B I$ values according to age $(P=0.805, r=-0.25, n=98)$.

Abbreviation: $\mathrm{MBI}$, maximum blink interval. 


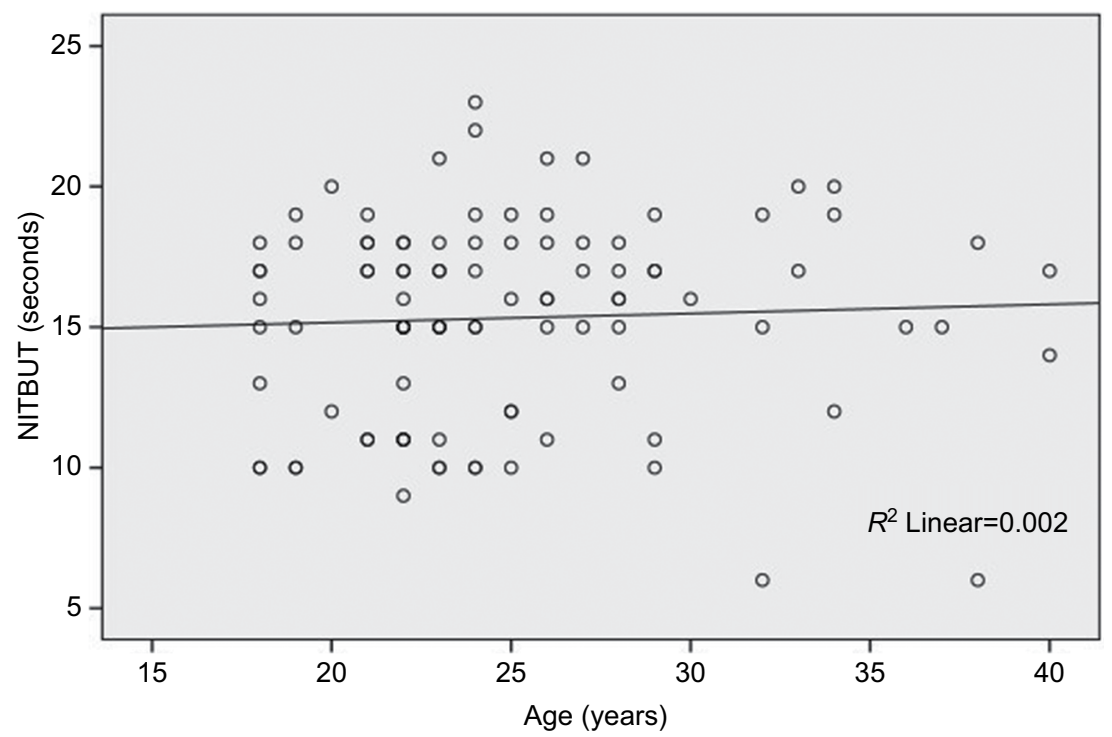

Figure 3 Distribution of NITBUT values according to age ( $P=0.64 \mathrm{I}, \mathrm{r}=0.48, \mathrm{n}=98)$.

Abbreviation: NITBUT, non-invasive tear break-up time.

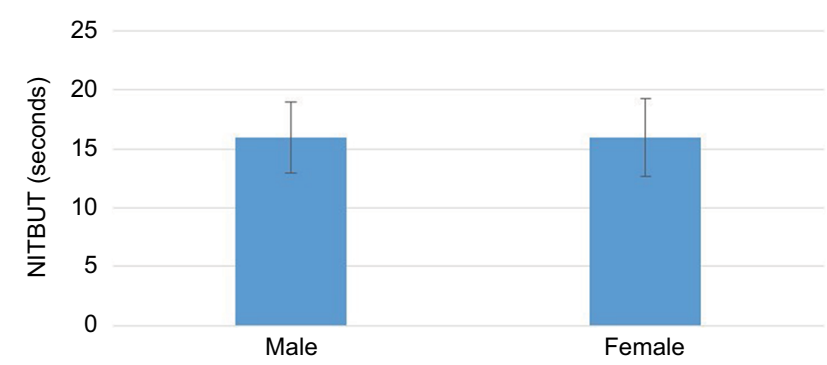

Figure 4 Distribution of NITBUT values according to gender. Abbreviation: NITBUT, non-invasive tear break-up time.

registered a mean $\mathrm{MBI}$ value of $21 \mathrm{~s}(\mathrm{SD}=6.01 \mathrm{~s}) ; \mathrm{t}(96)=0.4$, $P=0.629$.

\section{Distribution of NITBUT values according to gender}

The average NITBUT values observed among female and male subjects were equal. Male subjects had an average NITBUT value of $16 \mathrm{~s}(\mathrm{SD}=3.02 \mathrm{~s})$, and female subjects had an average NITBUT value of $16 \mathrm{~s}(\mathrm{SD}=3.29 \mathrm{~s})$. Figure 4 shows the distribution NITBUT values according to gender.

\section{Discussion}

\section{Relationship between NITBUT and MBI values}

Our study found that there is a significant correlation $(\mathrm{r}=0.6$, $\left.\mathrm{r}^{2}=0.418, P<0.001\right)$ between NITBUT and MBI values, which is in agreement with Glasson et al,,${ }^{14}$ who found a significant correlation between the two variables at the University of
New South Wales. The results of our study are also similar to a study by Liu et al, ${ }^{15}$ although they used invasive TBUT. Liu et $\mathrm{a}{ }^{15}$ presented a significant correlation between TBUT and MBI values.

This study indicates that the relationship between NITBUT and MBI values in Malawi, Africa, is the same as in other parts of the world, with different climatic conditions. This is in contrast with Patel et al, ${ }^{16}$ who suggested that TBUT findings may vary across different climatic conditions as well as geographical settings. Therefore, with regard to different climatic conditions in different environments, the relationship between NITBUT and MBI values is the same as evidenced by similar findings of studies conducted in different continents with different climatic conditions.

\section{Distribution of NITBUT and MBI values according to age}

Our study results showed that there was no correlation between age and MBI values, and also between age and NITBUT values. This is in agreement with Amaechi and Osunwoke, ${ }^{17}$ who reported that there is no correlation between age and the tear film stability. However, other authors ${ }^{2,18}$ reported a negative correlation between age and NITBUT. The differences in correlations between the tear film stability and age may be due to differences in the age groups used among different studies.

For instance, this study, and the study by Amaechi and Osunwoke, ${ }^{17}$ employed a narrow range of age. Our study included subjects ranging from 18 to 40 years, and Amaechi and Osunwoke ${ }^{17}$ recruited subjects ranging from 20 to 
30 years, while Ozdemir and Temizdemir ${ }^{18}$ included subjects with a wide age range ( $20-80$ years).

Our study reports no correlation between age and NITBUT/MBI, and this could be because the study had employed a narrow age range (18-40 years), hence there would be little aging effects of dry eye seen.

\section{Distribution of NITBUT and MBI values according to gender}

The study results showed that there is no differences between NITBUT and MBI values with respect to gender. A similar trend of NITBUT and MBI values was observed in both males and females in studies by Mishra et al, ${ }^{19}$ Yee et al, ${ }^{2}$ and Ozdemir and Temizdemir. ${ }^{18}$ This signifies that there is no tear film difference with respect to gender.

However, results of this study differ from a study by Maissa and Guillon, ${ }^{20}$ who noted that there are lower NITBUT values among females under the age of 45 years as compared to males. They further reported that, beyond the age of 45 years, the average NITBUT values for both genders were equal.

\section{Conclusion}

This study had investigated the relationship between NITBUT and MBI values among young adults at Mzuzu University. The study results showed a positive significant correlation $\left(\mathrm{r}=0.6, \mathrm{r}^{2}=0.418, P<0.001\right)$ between NITBUT and MBI values. It has also been discovered that the relationship between NITBUT and MBI values is equal among males and females. The study has also discovered that there is no correlation of NITBUT and MBI values with age and gender.

\section{Disclosure}

The authors report no conflicts of interest in this work.

\section{References}

1. Dry Eye Workshop. The definition and classification of dry eye disease: report of the Definition and Classification Subcommittee of the International Dry Eye WorkShop (2007). Ocul Surf. 2007;5:75-92.
2. Sharanjeet-Kaur, Ho CY, Mutalib HA, Ghazali AR. The relationship between tear ferning patterns and non-invasive tear break-up time in normal Asian population. J Optom. 2016;9:175-181.

3. Gayton JL. Etiology, prevalence, and treatment of dry eye disease. Clin Ophthalmol. 2009;3:405-412.

4. Miljanović B, Dana R, Sullivan DA, Schaumberg DA. Impact of dry eye syndrome on vision-related quality of life. Am J Ophthalmol. 2007;143:409-415.

5. Le Q, Zhou X, Ge L, Wu L, Hong J, Xu J. Impact of dry eye syndrome on vision-related quality of life in a non-clinic-based general population. BMC Ophthalmol. 2012;12:22.

6. Ng AL, To KK, Choi CC, et al. Predisposing factors, microbial characteristics, and clinical outcome of microbial keratitis in a tertiary centre in Hong Kong: a 10-year experience. J Ophthalmol. 2015;2015:769436.

7. Xu KP, Yagi Y, Tsubota K. Decrease in corneal sensitivity and change in tear function in dry eye. Cornea. 1996;15:235-239.

8. Hauswirth SG. When dry eye compromises corneal integrity. Review of Optometry website; 2017. Available from: https://www.reviewofoptometry.com/article/ro1117-when-dry-eye-compromises-cornealintegrity\#footnotes. Accessed April 8, 2018.

9. Henderson R, Madden L. Dry-eye management. Optom Pract. 2013;14:137-146.

10. Sweeney DF, Millar TJ, Raju SR. Tear film stability: a review. Exp Eye Res. 2013;117:28-38.

11. Yamane T. Statistics: an introductory analysis. 2nd ed. New York: Harper and Row; 1967.

12. Terry R, Williams L, Toit R. Diagnosis \& management of dry eye in contact lens wear. Australia: The International Association of Contact Lens Educators; 1997. Available from: https://www.iacle.org/index. php?option=com_content\&view $=$ article\&id=322. Accessed July 13, 2018.

13. Nakamori K, Odawara M, Nakajima T, Mizutani T, Tsubota K. Blinking is controlled primarily by ocular surface conditions. Am J Ophthalmol. 1997;124:24-30.

14. Glasson MJ, Stapleton F, Keay L, Sweeney D, Willcox MD. Differences in clinical parameters and tear film of tolerant and intolerant contact lens wearers. Invest Ophthalmol Vis Sci. 2003;44:5116-5124.

15. Liu H, Begley CG, Chalmers R, Wilson G, Srinivas SP, Wilkinson JP. Temporal progression and spatial repeatability of tear breakup. Optom Vis Sci. 2006;83:723-730.

16. Patel S, Virhia SK, Farrell P. Stability of the precorneal tear film in Chinese, African, Indian, and caucasian eyes. Optom Vis Sci. 1995;72:911-915.

17. Amaechi OU, Osunwoke CM. The relation between invasive and noninvasive tear break-up time in young adults. J Niger Optom Assoc. 2004;11:29-32.

18. Ozdemir M, Temizdemir H. Age- and gender-related tear function changes in normal population. Eye. 2010;24:79-83

19. Mishra P, Srivastava D, Misra R, Malik VK, Trivedi V. Assessment of tear secretions in healthy Indian volunteers. Indian J Physiol Pharmacol. 2014;58:137-140.

20. Maissa C, Guillon M. Tearfilm dynamics and lipid layer characteristics effect of age and gender. Cont Lens Anterior Eye. 2010;33:176-182.
Clinical Optometry

\section{Publish your work in this journal}

Clinical Optometry is an international, peer-reviewed, open access journal publishing original research, basic science, clinical and epidemiological studies, reviews and evaluations on clinical optometry. All aspects of patient care are addressed within the journal as well as the practice of optometry including economic and business analyses. Basic and clinical
Dovepress

research papers are published that cover all aspects of optics, refraction and its application to the theory and practice of optometry. The manuscript management system is completely online and includes a very quick and fair peer-review system, which is all easy to use. Visit http://www.dovepress. com/testimonials.php to read real quotes from published authors. 